their orbits in each atom is related to the temperature -if the temperature is greatly increased they begin to fly round so rapidly that eventually one of them flies off altogether by a kind of centrifugal force" are statements in a class by themselves. The introduction to radio as the propagation of "electromagnetic and electrostatic" waves by a process of electrostatic induction is unfortunately plausible. The old international ohm is defined as a piece of platinum preserved somewhere, and even the statement of Ohm's law would not be accepted in an Ordinary-level physics examination. The unwritten law (which should be restricted to the same category of book) requiring a certain tempering of the scientific usage of the terms force, work, and power for the layman, so that they are used correctly in some places and interchangeably in others, has been operative here.

The pity is that blemishes of this kind in an attractive and otherwise excellent book should, because they are barely relevant to its main message to the general reader, appear to be trivial. They greatly reduce its value for the student to whom it is also directed, for he cannot afford to take that point of view. In guide-book terms, this does the tourist handsomely and treats the fell-walker pretty well ; but it is not for those who also want a little serious climbing.

G. R. NOAKES

\section{PROBLEMS OF TECHNICAL LIBRARY SERVICES IN GREAT BRITAIN}

\section{Commercial and Technical Libraries}

By J. P. Lamb. (The Library Association Series of Library Manuals-10.) Pp. $316+7$ plates. (London : George Allen and Unwin, Ltd., and the Library Association, 1955.) 21s, net.

THEE Sheffield City Librarian, Mr. J. P. Lamb, has long been known outside the circle of public librarians for his part in the highly successful interchange scheme for technical publications which he first described to an Aslib Conference more than twenty years ago. This latest book of his is addressed primarily to those concerned with the running of a public commercial and technical library. While, however, his chapters on the equipment and staffing of such a library, the principles which should determine its relation to the public library system generally or the selection of its stock, whether of books and periodicals or of patent specifications, are chiefly of interest to those engaged in such work, the imagination and shrewd common sense which have contributed so much to the success of the Sheffield scheme continually break through and give his chapters a wider interest or relevance. Always he is impatient of operational ineptitude or of grandiose schemes which have little relation to reality, whether it be for book coverage or anything else. $\mathrm{He}$ is keenly alive to the fact that libraries are for use, and this pervading sense of users' needs makes such a chapter as that on organization and administration as interesting to the general reader as to the librarian.

To the technical librarian in industry these chapters are almost as useful and suggestivo as they are to the librarian engaged in public library service, and parts of them will interest the technologist and scientist. To such, and perhaps to the industrialist generally, the chapter on external activities will be of no less interest, and many will be surprised at the scope and extent of the activities of the technical information departments which are already maintained by some public libraries. Mr. Lamb's account is the more welcome in that, as he duly points out, an inquiry in this field made by the Federation of British Industries, in collaboration with the Panel on Technical Information Services of the Committee on Industrial Productivity, largely overlooked what was being done by the public libraries and gave no indication of the extent to which such activities enable commercial and industrial concerns to economize in the information services they them. selves maintain.

In Great Britain the smaller firms especially are as yet barely conscious of the needs which the public commercial or technical library could thus meet, and Mr. Lamb is rightly critical of this omission in an important report, the paragraphs of which relating specifically to public libraries he quotes in full in his final chapter. It is this chapter and that in which he reviews briefly the history of British commercial and technical libraries and notes some of the missed opportunities of the inter-war years that are of most interest to the general reader as well as to the scientist. To the latter this concluding chapter, with its admirably balanced survey of the future in which proposals, for example, for a science centre, including a national lending library of science and technology as well as a national reference library for that field, are placed in their proper perspective in relation to the existing library resources of Britain, including those of the public library system, is absorbing.

This chapter, which displays clearly the bearing of an efficient technical library system on technical education, industrial research and industrial efficiency in general, is of particular interest at the moment in that, since this book was written, the Advisory Council on Scientific Policy, in its eighth annual report, reverts again to the place of scientific libraries in the national economy, both in securing the most effective use of the nation's scientific and technical man-power and in furthering the dissemination of technical information as well as the development of higher technological education. In this respect Mr. Lamb's account needs amplifying, for as it stands it suggests that the Advisory Council has dropped its support for the project of a national lending library. For all that, his chapter admirably states the case for a national lending library and a national reference library and for the way in which both could be supported by existing public technical library services. It gives a concise but clear picture of the advantages and economy to be derived from a carefully thoughtout policy of utilizing to the full existing services, but providing at the centre the essential national services to which the Advisory Council on Scientific Policy points.

The limitations of interchange schemes are clearly recognized; but none the less, Mr. Lamb puts clearly and fairly both the advantages of such schemes in relieving pressure on a national lending library of science and technology and the case for a government grant to those public technical libraries which, by co-operating in this and other ways with the national lending reference library, would increase its efficiency and resources and secure a better use of the nation's existing resources and services, whether in the way of books and periodicals or of trained staff.

\section{R. Brightman}

